\title{
Association of leptin, visfatin, apelin, resistin and adiponectin with clear cell renal cell carcinoma
}

\author{
HAI-PING ZHANG ${ }^{1}$, JIAN ZOU ${ }^{2}$, ZHUO-QUN XU ${ }^{3}$, JUN RUAN ${ }^{3}$, \\ SHU-DONG YANG ${ }^{4}$, YING YIN $^{2}$ and HUI-JUN MU ${ }^{2}$ \\ ${ }^{1}$ Department of Derma Science Laboratory, Wuxi No. 2 People's Hospital Affiliated to Nanjing Medical University, \\ Wuxi, Jiangsu 214002; Departments of ${ }^{2}$ Clinical Laboratory Science, ${ }^{3}$ Urinary Surgery and ${ }^{4}$ Pathology, \\ Wuxi People's Hospital Affiliated to Nanjing Medical University, Wuxi, Jiangsu 214023, P.R. China
}

Received March 11, 2015; Accepted November 3, 2016

DOI: $10.3892 / \mathrm{ol} .2016 .5408$

\begin{abstract}
Although an association between obesity and the occurrence of renal cell carcinoma (RCC) has been identified, the mechanism by which obesity functions to increase this risk of cancer remains unclear. Leptin, visfatin, apelin, resistin and adiponectin are peptide hormones secreted by adipocytes; it is considered that these may affect RCC development by exerting effects on proliferation, cell growth and inflammation. The aim of the present study was to investigate the association between the aforementioned adipokine genes and clear cell RCC (CC-RCC). The GSE6344 dataset was downloaded from the Gene Expression Omnibus database, and the relative expression levels of the adipokine genes were analyzed. To verify the results of the mRNA microarray, 77 paired samples of CC-RCC and corresponding adjacent normal tissue were allocated into two groups. The extraction of total RNA was conducted, and the mRNA expression of adipokine genes was analyzed using reverse transcription-quantitative polymerase chain reaction (RT-qPCR). The data from the GSE6344 dataset indicated that the expression of visfatin and apelin was upregulated $(\mathrm{P}<0.0001$ and $\mathrm{P}<0.01$, respectively), and adiponectin was downregulated $(\mathrm{P}<0.001)$ in the CC-RCC tissues compared with the adjacent normal tissues. The data from RT-qPCR demonstrated that visfatin and resistin gene expression was increased $(\mathrm{P}<0.01$ and $\mathrm{P}<0.05$, respectively) in the CC-RCC tissues. Furthermore, the mRNA expression level of leptin and adiponectin in the adjacent normal tissue was higher than those in the cancer tissue $(\mathrm{P}<0.01)$. The current study verifies that visfatin and adiponectin are associated with an increased risk of CC-RCC,
\end{abstract}

Correspondence to: Mr. Hui-Jun Mu, Department of Clinical Laboratory Science, Wuxi People's Hospital Affiliated to Nanjing Medical University, 299 Qing Yang Road, Wuxi, Jiangsu 214023, P.R. China

E-mail:wxmuhj@gmail.com

Key words: leptin, visfatin, apelin, resistin, adiponectin, renal cell carcinoma which presents further insights into the molecular mechanisms of CC-RCC tumorigenesis.

\section{Introduction}

Renal cell carcinoma (RCC) is one of the most lethal types of cancer within the urinary system, and up to one-third of patients with RCC already present with primary metastases at the time of diagnosis (1). RCC is categorized into four major subtypes according to the Heidelberg classification system (2): i) Clear cell RCC (CC-RCC); ii) papillary RCC: iii) chromophobe RCC; and iv) renal oncocytoma. CC-RCC is the most prevalent subtype of RCC, accounting for $\sim 80 \%$ of cases (3). Specific molecular mechanisms have been identified in RCC tumorigenesis, including von Hipple-Lindau gene mutation (4). Somatic mutation of this gene has been associated with the development of $\sim 60 \%$ of sporadic CC-RCC (5). However, no current theory is able to explain all cases of CC-RCC development. To understand the pathogenesis of CC-RCC in detail, further research is warranted.

A number of epidemiological studies have connected the occurrence of renal cancer to obesity (6-8). A specific association between obesity and RCC has been established, however, the mechanism by which obesity increases the risk of cancer remains unclear (9). Recently, certain obesity-associated biomarkers have been identified and are considered as a possible link between the two features (10). Among these biomarkers, the adipokines are of particular note. Adipokines, including adiponectin, leptin, resistin, visfatin and apelin, are peptide hormones secreted primarily by adipose tissue and are associated with metabolic syndrome (11). Studies have identified that adipokines affect various pro-neoplastic mechanisms, including inflammation, cell growth and proliferation $(12,13)$. Studies have also demonstrated that adipokines are promising predictors of risk and progression in various types of cancer $(14,15)$. Such evidence suggests that adipokines contribute to the initiation of carcinogenesis and tumor progression.

Microarray technology provides a wide range of information regarding molecules that have been associated with disease pathogenesis, and subsequently aids the elucidation of the underlying molecular mechanisms of disease. To gain insights into the pathogenesis of $\mathrm{CC}-\mathrm{RCC}$, several gene expression 
Table I. Sequences of primers used for reverse transcription-quantitative polymerase chain reaction analysis of the adipokine genes and the GAPDH gene.

\begin{tabular}{lll}
\hline Gene & Orientation & \multicolumn{1}{c}{ Primer sequence (5'-3') } \\
\hline GAPDH & Forward & CAACTTTGGTATCGTGGAAGGACTC \\
\multirow{2}{*}{ Leptin } & Reverse & AGG GATGATGTTCTGGAGAGCC \\
& Forward & CGTTAAGGGAAGGAACTCTGG \\
Resistin & Reverse & TGGCTTAGAGGAGTCAGGGA \\
& Forward & GTGTGCCGGATTTGGTTAGC \\
Visfatin & Reverse & AGGAGGAGGAGACAGAGAGC \\
& Forward & CTTCGGTTCTGGTGGAGGTT \\
Apelin & Reverse & ATCGGCCCTTTTGGACCTT \\
& Forward & GCTGACAGTTCGCCCTTACT \\
Adiponectin & Reverse & ATATGTGGGCATGGGGACAC \\
& Forward & ATGGCCCCTGCACTACTCTA \\
& Reverse & CAGGGATGAGTTCGGCACTT
\end{tabular}

profiling studies have been conducted analyzing differences between tumor and normal tissue (16,17). Such studies have identified a number of differentially-expressed genes, including the adipokine genes. In the present study, to investigate the association between adipokine genes and the molecular mechanisms of RCC, gene expression profiles of $10 \mathrm{CC}-\mathrm{RCC}$ and 10 adjacent normal tissue controls were downloaded from the Gene Expression Omnibus (GEO) database, and the relevant adipokine gene data was analyzed. To verify the results of mRNA microarray, the expression of various adipokine genes were analyzed in $77 \mathrm{CC}$-RCC patients using reverse transcription-quantitative polymerase chain reaction (RT-qPCR). The present study aimed to identify the underlying mechanisms of obesity that may result in an increased risk of CC-RCC.

\section{Materials and methods}

Patients. In the current study, a total of 77 patients were enrolled, who had been histologically diagnosed with CC-RCC between December 2005 and September 2012. The patients consisted of 14 females and 63 males, with ages ranging from 17 to 85 years (mean \pm standard deviation, $56.22 \pm 12.27$ years).

All protocols were approved by the ethics committee of Wuxi People's Hospital Affiliated to Nanjing Medical University (Wuxi, China) prior to the initiation of the study, and the protocols conformed to the ethical guidelines of the 1975 Helsinki Declaration. Informed consent was obtained from each patient prior to surgery.

RNA extraction. Tumor tissue samples and corresponding adjacent normal tissues were obtained from resection surgical specimens, and were immediately dissociated into single cells using the Medimachine system (BD Biosciences, Franklin Lakes, NJ, USA). The cells were then dissolved in $1 \mathrm{ml}$ Trizol $^{\circledR}$ reagent (Invitrogen; Thermo Fisher Scientific, Inc., Waltham, MA, USA) and stored at $-80^{\circ} \mathrm{C}$. Total cellular RNA was extracted using the Trizol reagent following the manufacturer's protocols. The quantity and purity of RNA were determined with the Beckman DU-640 Spectrophotometer (Beckman Coulter, Inc., Brea, CA, USA).
Reverse transcription reaction. Total RNA $(2 \mu \mathrm{g})$ and $200 \mathrm{ng}$ random primer (Sangon Biotech Co., Ltd., Shanghai, China) were added to $15 \mu$ l diethylpyrocarbonate (DEPC) treated with $\mathrm{H}_{2} \mathrm{O}$; this was subsequently incubated at $65^{\circ} \mathrm{C}$ for $5 \mathrm{~min}$ and then cooled rapidly on ice. Following this, $2.0 \mu 1$ DEPC $\mathrm{H}_{2} \mathrm{O}$, $5.0 \mu 15 X$ RT buffer (containing $375 \mathrm{mM} / 1 \mathrm{KCl}, 250 \mathrm{mM} / 1$ Tris- $\mathrm{HCl}, 3 \mathrm{mM} / 1 \mathrm{MgCl}_{2}$ and $50 \mathrm{mM} / \mathrm{l}$ dithiothreitol), $1.25 \mu \mathrm{l}$ $10 \mathrm{mM} / 1$ deoxynucleoside triphosphate (dNTP; Sangon Biotech Co., Ltd.), $0.75 \mu 140$ U/ $\mu 1$ RNAsin (Sangon Biotech Co., Ltd.) and 1.0 $\mu 1200$ U/ $\mu 1$ MMLV Reverse Transcriptase (Promega Corporation, Madison, WI, USA) were added, centrifuged at $1,000 \times \mathrm{g}$ for $30 \mathrm{sec}$ at $4^{\circ} \mathrm{C}$ and incubated at $37^{\circ} \mathrm{C}$ for $60 \mathrm{~min}$, and finally stored at $-20^{\circ} \mathrm{C}$.

Gene expression analysis using $R T-q P C R$. RT-qPCR was performed using the LightCycler ${ }^{\circledR} 480$ Real-Time PCR system (Roche Diagnostics, Basel, Switzerland). The primers utilized during PCR are presented in Table I. PCR was performed using a final volume of $20 \mu \mathrm{l}$, which contained $2 \mu 125 \mathrm{mM} / 1 \mathrm{MgCl}_{2}, 10 \mathrm{mM} / \mu \mathrm{l}$ sense and antisense primers (1.0 $\mu \mathrm{l}$ each), $0.4 \mu 110 \mathrm{mmol} / 1 \mathrm{dNTP}, 1.0 \mu 1$ EvaGreen ${ }^{\circledR}$ dye (Biotium Inc., Hayward, CA, USA), $2.0 \mu 1$ 5X PCR buffer (Promega Corporation), $2.0 \mu \mathrm{l}$ complementary DNA, 0.5 units Taq DNA Polymerase buffer (Promega Corporation) and up to $20 \mu 1 \mathrm{H}_{2} \mathrm{O}$. Following initial denaturation at $94^{\circ} \mathrm{C}$ for $2 \mathrm{~min}$, a total of 40 cycles were performed. Each cycle consisted of denaturation at $94^{\circ} \mathrm{C}$ for $5 \mathrm{sec}$, annealing at $58^{\circ} \mathrm{C}$ for $20 \mathrm{sec}$ and elongation at $72^{\circ} \mathrm{C}$ for $20 \mathrm{sec}$, followed by a single fluorescence measurement. Melting curve analyses of the amplified products were performed to confirm the specificity of qPCR assay. Samples were normalized using the housekeeping gene GAPDH.

Affymetrix microarray analysis. The gene expression profile of GSE6344 was downloaded from the National Center for Biotechnology Information GEO database, which is based on the Affymetrix Human Genome U133A Array platform (Affymetrix, Inc., Santa Clara, CA, USA). A total of 20 samples, including $10 \mathrm{CC}-\mathrm{RCC}$ and 10 adjacent normal tissue specimens, were available for GSE6344 microarray 


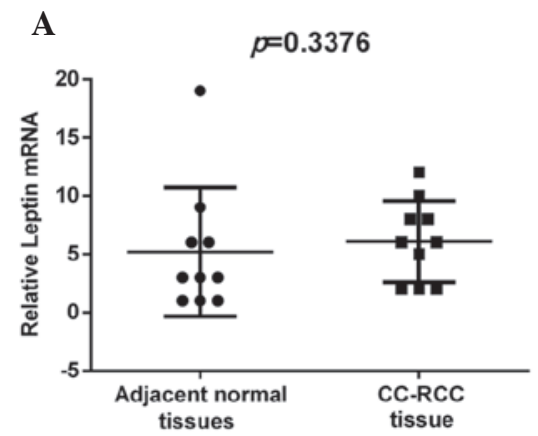

B

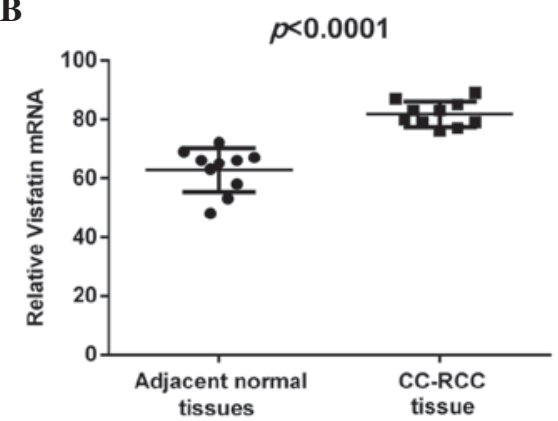

C

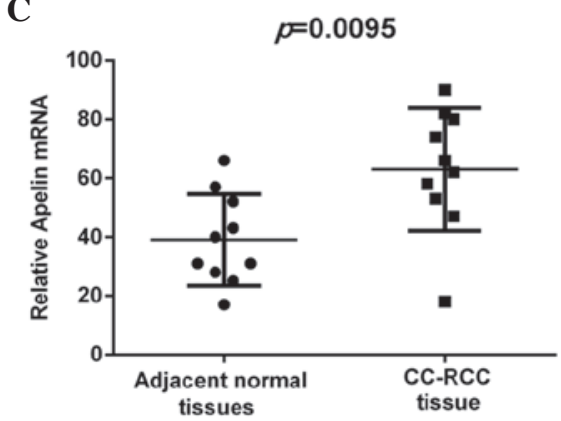

D

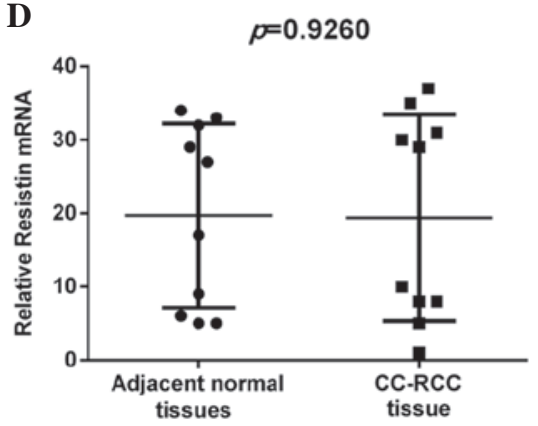

$\mathbf{E}$

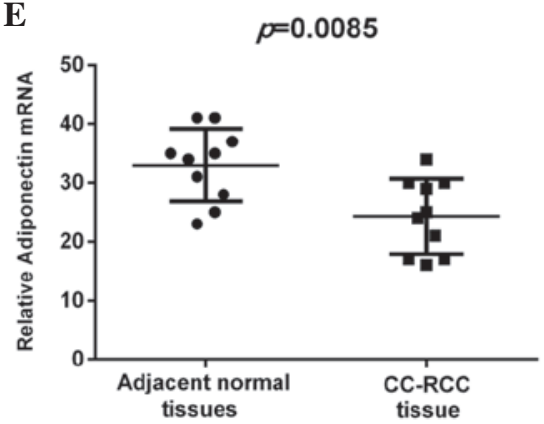

Figure 1. Analysis of (A) leptin, (B) visfatin, (C) apelin, (D) resistin and (E) adiponectin mRNA expression profiles in CC-RCC and adjacent normal tissues in the GSE6344 dataset. CC-RCC, clear cell renal cell carcinoma.

analysis. The original mRNA expression profile was standardized using rank value, and the relative expression levels of adipokine genes were analyzed.

Statistical analysis. Changes in adipokine genes expression between CC-RCC and adjacent normal tissues were determined by the comparative $\Delta \Delta \mathrm{Cq}$ method (18), using GAPDH as an internal reference. $\Delta \Delta \mathrm{Cq}=\Delta \mathrm{Cq}$ (CC-RCC group) $-\Delta \mathrm{Cq}$ (normal group) for RNA samples. Quantification cycle $(\mathrm{Cq})$ is defined as an index of the number of cycles required for the fluorescent signal to cross the threshold. $\triangle \mathrm{Cq}$ represents the difference in $\mathrm{Cq}$ values derived from the target gene (in each sample assayed) and the GAPDH gene, while $\Delta \Delta \mathrm{Cq}$ represents the difference between the paired samples. The n-fold differential ratio was expressed as $2{ }^{-\Delta \Delta \mathrm{Cq}}$. Comparisons between the samples (CC-RCC vs. adjacent normal tissue) were performed using a one-way analysis of variance. All statistical data were analyzed using SPSS software v15.0 (SPSS, Inc., Chicago, IL, USA). $\mathrm{P}<0.05$ was used to indicate a statistically significant difference. As compared with the adjacent normal tissue, genes in the CC-RCC tissue with statistically significant differences at $\mathrm{P}<0.05$ and a fold change of $\geq 1.5$ were considered as upregulated, whereas those with $\mathrm{P}<0.05$ with a fold change of $\leq 0.75$ were considered as downregulated. Comparisons between the samples (CC-RCC vs. adjacent normal tissue) in the GSE6344 dataset were performed using a non-parametric Mann-Whitney U test.

\section{Results}

Expression of leptin, visfatin, apelin, resistin and adiponectin mRNA in CC-RCC with Affymetrix microarray analysis. Analysis of leptin, visfatin, apelin, resistin and adiponectin relative expression was performed between the CC-RCC and adjacent normal tissues from the GSE6344 microarray dataset (Fig. 1). The GSE6344 dataset demonstrated that the expression of visfatin and apelin was upregulated $(\mathrm{P}<0.0001$ and $\mathrm{P}<0.01$, respectively), whilst adiponectin was downregulated $(\mathrm{P}<0.001)$ in the CC-RCC tissues compared with the adjacent normal tissues, relative to GAPDH. However, the expression of leptin and resistin exhibited no significant difference between the CC-RCC and adjacent normal tissues ( $\mathrm{P}>0.05)$.

Expression of leptin, visfatin, apelin, resistin and adiponectin mRNA in CC-RCC and adjacent normal tissue samples with $R T-q P C R$. RT-qPCR was used to confirm the results of gene microarray for the selected adipokine genes. Table II presents the mRNA expression of leptin, visfatin, apelin, resistin and adiponectin between the CC-RCC and adjacent normal tissues. The data demonstrated that visfatin and resistin gene expression was upregulated in the CC-RCC tissues $(\mathrm{P}<0.01$ and $\mathrm{P}<0.05$, respectively). However, the mRNA expression level of leptin and adiponectin in adjacent normal tissue was higher than that in the cancer tissue $(\mathrm{P}<0.01)$. The data also indicated that the expression of apelin was not significantly different between the CC-RCC and adjacent normal tissues ( $\mathrm{P}>0.05)$.

\section{Discussion}

Although obesity is recognized as a potent risk factor for RCC development (19), the mechanism through which it functions to increase RCC risk is unclear. Recently, adipokines have been thoroughly investigated as novel biomarkers that may indicate cancer risk. Adipokines, derived from adipose tissue, serve roles in lipid and glucose metabolism, regulation of energy balance and inflammatory processes (20). Adipokines are understood to be involved in certain obesity-associated forms of cancer, and serve a key role in tumorigenesis and 
Table II. mRNA expression profiles of adipokine in 77 patients with CC-RCC, acquired through reverse transcription-quantitative polymerase chain reaction.

\begin{tabular}{lccc}
\hline Gene & CC-RCC tissue, mean \pm SD & Adjacent normal tissue, mean \pm SD & $2^{-\Delta \Delta C q}$ \\
\hline Leptin $^{\mathrm{a}}$ & $30.61 \pm 1.62$ & $30.63 \pm 2.46$ & 0.37 \\
Resistin $^{\mathrm{b}}$ & $30.76 \pm 2.05$ & $32.90 \pm 1.31$ & 1.62 \\
Visfatin $^{\mathrm{a}}$ & $22.73 \pm 0.88$ & $25.24 \pm 1.07$ & 2.09 \\
Ampelin $_{\text {Adiponectin }}^{\mathrm{a}}$ & $28.31 \pm 1.61$ & $30.02 \pm 2.02$ & 1.20 \\
GAPDH & $31.57 \pm 1.99$ & $31.55 \pm 2.64$ & 0.37 \\
\hline
\end{tabular}

All results are expressed as the mean $\pm \mathrm{SD}$ of $\mathrm{Cq} .{ }^{\mathrm{a}} \mathrm{P}<0.01$ and ${ }^{\mathrm{b}} \mathrm{P}<0.05, \mathrm{CC}-\mathrm{RCC}$ vs. adjacent normal tissues. CC-RCC, clear cell renal cell carcinoma; SD, standard deviation.

prognosis $(21,22)$. To the best of our knowledge, the current study is the first to identify a difference in visfatin and apelin expression levels in CC-RCC and control tissues. Furthermore, several studies have reported a difference in leptin, resistin and adiponectin serum levels in CC-RCC tissues $(23,24)$. However, the physiological role of leptin and adiponectin in CC-RCC remains controversial. Therefore, in the present study, the mRNA expression variation of visfatin, resistin, apelin, leptin and adiponectin was investigated in CC-RCC.

Leptin is a multifunctional peptide hormone that regulates energy expenditure (25), promotes proliferation (26) and angiogenesis (27), and inhibits cell apoptosis (28). Studies have demonstrated that leptin levels are higher in lung cancer (15), breast cancer (29) and RCC (30), whilst other studies have reported that serum leptin levels are inversely associated with RCC risk (23) or are not significantly associated with RCC $(24,31)$. These contradictory results, and the serum level features, suggest that further investigation is required. The microarray analysis from the present study demonstrated that the expression of leptin exhibited no significant difference between the CC-RCC and adjacent normal tissues. However, it was also identified that the mRNA expression level of leptin in the CC-RCC tissues was significantly lower than that in the adjacent normal tissues with RT-qPCR.

Visfatin is an adipokine associated with obesity and glucose regulation. Visfatin was originally identified as a cytokine and was termed pre-B cell-enhancing factor, also known as Nampt (32). The adipokine possesses nicotinamide adenine dinucleotide biosynthetic activity and regulates mammalian cell growth and apoptosis (33); it is also known to promote novel blood vessel formation and migration (34). The function of visfatin in carcinogenesis and as a chemotherapeutic target has gained the increasing attention of researchers. Studies have reported that the expression of visfatin is correlated with various types of cancer, including breast (35), colorectal (36) and gastric (37) cancer. However, to the best of our knowledge, the association between visfatin and CC-RCC has not been confirmed until now. In the present study, the GSE6344 dataset demonstrated that the expression of visfatin was upregulated in the CC-RCC tissues compared to the adjacent normal tissues. The RT-qPCR data of 77 CC-RCC patients also indicated that visfatin gene expression was upregulated.
Apelin, a recently described adipokine, is a mitogenic factor expressed in endothelial cells (38). Apelin is involved in the process of cell proliferation (39) and stimulates cancer angiogenesis (40). A case-control study observed that serum apelin levels increased significantly in patients with gastroesophageal cancer (41). However, there is no epidemiological data regarding the association between apelin and CC-RCC risk. The GSE6344 dataset demonstrates that the expression of apelin was upregulated in the CC-RCC tissues compared to the adjacent normal tissues. However, the RT-qPCR data indicated that the expression of apelin was not significantly different between the CC-RCC and adjacent normal tissues $(\mathrm{P}>0.05)$.

Resistin is a member of the recently identified family of cysteine-rich proteins; it is the primary product of macrophages that infiltrates into adipose tissue (42), and has been associated with adiposity, inflammation and insulin resistance (43). Resistin serum concentrations have been observed to be significantly higher in patients with cancer than in controls $(41,44)$. However, one study has reported that circulating levels of resistin are not associated with RCC (24). In the present study, the GSE6344 dataset demonstrated that the expression of resistin exhibited no significant difference between the CC-RCC and adjacent normal tissues. However, the RT-qPCR data indicated that the mRNA expression level of resistin in the CC-RCC tissues was significantly higher than that in the adjacent normal tissues.

Adiponectin is a circulating adipokine secreted by mature adipocytes. The circulating level of adiponectin is inversely associated with insulin resistance and obesity (45). Abundant evidence indicates that adiponectin suppresses the growth of cancer cells and reduces the risk of cancer $(14,46)$. Studies have reported that serum adiponectin levels are inversely associated with RCC, and breast and colon cancer $(47,48)$. While the preponderance of evidence suggests that an inverse association exists between adiponectin and malignancy, another study reported that higher levels of serum adiponectin were associated with RCC risk, specifically among African-American males (31). Enhanced adiponectin serum concentrations appear to indicate inflammatory status and advanced stages of malignancy $(49,50)$. However, all aforementioned studies were confined to studying adiponectin levels within the circulatory system. In the present study, the RT-qPCR data indicated that 
the mRNA expression level of adiponectin in the CC-RCC tissues was significantly lower than that of the adjacent normal tissues, which was consistent with the GSE6344 dataset.

Microarray technology provides a wide range of information regarding molecules that are associated with disease pathogenesis. However, the high cost of detection limits the application in larger samples, which may lead to reduced sensitivity. RT-qPCR is the gold standard for verification of microarray data. In the present study, the data regarding visfatin and adiponectin is consistent between microarray and RT-qPCR. However, the data concerning leptin, resistin and apelin from RT-qPCR cannot verify the results from the GSE6344 microarray dataset. This may be attributed to the small sample size of the GSE6344 microarray. Furthermore, it was demonstrated in another study that the expression level of leptin varies in different ethnicities (31), which may lead to the contradictory results.

In conclusion, such findings suggest that visfatin and resistin are high-risk factors for the development of CC-RCC. By contrast, leptin and adiponectin are inversely associated with CC-RCC risk. The present study may provide novel information concerning the role of adipokines in CC-RCC risk. Due to the relatively small number of patients and contradictory results from microarray data, further studies are required to investigate the etiological significance of adipokine levels in CC-RCC risk.

\section{Acknowledgements}

The study was funded by a grant from the Wuxi Hospital Management Center (no. YGZ1102).

\section{References}

1. Fujioka Tand Obara W; Committee forEstablishment of the Clinical Practice Guideline for the Management of Renal Cell Carcinoma and the Japanese Urological Association: Evidence-based clinical practice guideline for renal cell carcinoma: The Japanese Urological Association 2011 update. Int J Urol 19: 496-503, 2012.

2. Kovacs G, Akhtar M, Beckwith BJ, Bugert P, Cooper CS, Delahunt B, Eble JN, Fleming S, Ljungberg B, Medeiros LJ, et al: The Heidelberg classification of renal cell tumours. J Pathol 183: 131-133, 1997.

3. Shenoy N and Pagliaro L: Sequential pathogenesis of metastatic VHL mutant clear cell renal cell carcinoma: Putting it together with a translational perspective. Ann Oncol 27: 1685-1695, 2016.

4. Razafinjatovo C, Bihr S, Mischo A, Vogl U, Schmidinger M, Moch H and Schraml P: Characterization of VHL missense mutations in sporadic clear cell renal cell carcinoma: Hotspots, affected binding domains, functional impact on pVHL and therapeutic relevance. BMC Cancer 16: 638, 2016.

5. Arjumand W and Sultana S: Role of VHL gene mutation in human renal cell carcinoma. Tumour Biol 33: 9-16, 2012.

6. Adams KF, Leitzmann MF, Albanes D, Kipnis V, Moore SC, Schatzkin A and Chow WH: Body size and renal cell cancer incidence in a large US cohort study. Am J Epidemiol 168 268-277, 2008

7. Luo J, Margolis KL, Adami HO, Lopez AM, Lessin L and Ye W; Women's Health Initiative Investigators: Body size, weight cycling, and risk of renal cell carcinoma among postmenopausal women: The Women's Health Initiative (United States). Am J Epidemiol 166: 752-759, 2007.

8. Lipworth L, Tarone RE, Lund L and McLaughlin JK: Epidemiologic characteristics and risk factors for renal cell cancer. Clin Epidemiol 1: 33-43, 2009.

9. Calle EE and Kaaks R: Overweight, obesity and cancer: Epidemiological evidence and proposed mechanisms. Nat Rev Cancer 4: 579-591, 2004.
10. Fischer-Posovszky $\mathrm{P}$, Wabitsch $\mathrm{M}$ and Hochberg $\mathrm{Z}$ : Endocrinology of adipose tissue - an update. Horm Metab Res 39: 314-321, 2007.

11. Raucci R, Rusolo F, Sharma A, Colonna G, Castello G and Costantini S: Functional and structural features of adipokine family. Cytokine 61: 1-14, 2013.

12. Balistreri CR, Caruso C and Candore G: The role of adipose tissue and adipokines in obesity-related inflammatory diseases. Mediators Inflamm 2010: 802078, 2010.

13. Riondino S, Roselli M, Palmirotta R, Della-Morte D, Ferroni P and Guadagni F: Obesity and colorectal cancer: Role of adipokines in tumor initiation and progression. World J Gastroenterol 20: 5177-5190, 2014.

14. Ye J, Jia J, Dong S, Zhang C, Yu S, Li L, Mao C, Wang D, Chen J and Yuan G: Circulating adiponectin levels and the risk of breast cancer: A meta-analysis. Eur J Cancer Prev 23: 158-165, 2014.

15. Song CH, Liao J, Deng ZH, Zhang JY, Xue H, Li YM, Liang C, Han M, Zhang K and Yan GT: Is leptin a predictive factor in patients with lung cancer? Clin Biochem 47: 230-232, 2014.

16. Tun HW, Marlow LA, von Roemeling CA, Cooper SJ, Kreinest $P$, Wu K, Luxon BA, Sinha M, Anastasiadis PZ and Copland JA: Pathway signature and cellular differentiation in clear cell renal cell carcinoma. PLoS One 5: e10696, 2010.

17. Lenburg ME, Liou LS, Gerry NP, Frampton GM, Cohen HT and Christman MF: Previously unidentified changes in renal cell carcinoma gene expression identified by parametric analysis of microarray data. BMC Cancer 3: 31, 2003.

18. Livak KJ and Schmittgen TD: Analysis of relative gene expression data using real-time quantitative PCR and the 2(-Delta Delta C(T)) Method. Methods 25: 402-408, 2001.

19. Gati A, Kouidhi S, Marrakchi R, El Gaaied A, Kourda N, Derouiche A, Chebil M, Caignard A and Perier A: Obesity and renal cancer: Role of adipokines in the tumor-immune system conflict. OncoImmunology 3: e27810, 2014.

20. Gulen ST, Karadag F, Karul AB, Kilicarslan N, Ceylan E, Kuman NK and Cildag O: Adipokines and systemic inflammation in weight-losing lung cancer patients. Lung 190: 327-332, 2012.

21. Ntikoudi E, Kiagia M, Boura Pand Syrigos KN: Hormones of adipose tissue and their biologic role in lung cancer. Cancer Treat Rev 40: 22-30, 2014.

22. Gonullu G, Kahraman H, Bedir A, Bektas A and Yücel I: Association between adiponectin, resistin, insulin resistance, and colorectal tumors. Int J Colorectal Dis 25: 205-212, 2010.

23. Spyridopoulos TN, Petridou ET, Dessypris N, Terzidis A, Skalkidou A, Deliveliotis C and Chrousos GP; Obesity and Cancer Oncology Group: Inverse association of leptin levels with renal cell carcinoma: Results from a case-control study. Hormones (Athens) 8: 39-46, 2009.

24. Liao LM, Weinstein SJ, Pollak M, Li Z, Virtamo J, Albanes D, Chow WH and Purdue MP: Prediagnostic circulating adipokine concentrations and risk of renal cell carcinoma in male smokers. Carcinogenesis 34: 109-112, 2013.

25. Shimizu H and Mori M: Role of leptin and its receptor in the regulation of appetite and body fat. Nihon Rinsho 59: 421-426, 2001 (In Japanese).

26. Yuan HJ, Sun KW and Yu K: Leptin promotes the proliferation and migration of human breast cancer through the extracellular-signal regulated kinase pathway. Mol Med Rep 9: 350-354, 2014.

27. Zhou W, Guo S and Gonzalez-Perez RR: Leptin pro-angiogenic signature in breast cancer is linked to IL-1 signalling. Br J Cancer 104: 128-137, 2011.

28. Chen C, Chang YC, Lan MS and Breslin M: Leptin stimulates ovarian cancer cell growth and inhibits apoptosis by increasing cyclin D1 and Mcl-1 expression via the activation of the MEK/ERK1/2 and PI3K/Akt signaling pathways. Int J Oncol 42: $1113-1119,2013$

29. Mohammadzadeh G, Ghaffari MA, Bafandeh A and Hosseini SM: Association of serum soluble leptin receptor and leptin levels with breast cancer. J Res Med Sci 19: 433-438, 2014.

30. Horiguchi A, Sumitomo M, Asakuma J, Asano T, Zheng R, Asano T, Nanus DM and Hayakawa M: Increased serum leptin levels and over expression of leptin receptors are associated with the invasion and progression of renal cell carcinoma. J Urol 176: 1631-1635, 2006.

31. Liao LM, Schwartz K, Pollak M, Graubard BI, Li Z, Ruterbusch J, Rothman N, Davis F, Wacholder S, Colt J, et al: Serum leptin and adiponectin levels and risk of renal cell carcinoma. Obesity (Silver Spring) 21: 1478-1485, 2013. 
32. Stastny J, Bienertova-Vasku J and Vasku A: Visfatin and its role in obesity development. Diabetes Metab Syndr 6: 120-124, 2012.

33. Bi TQ and Che XM: Nampt/PBEF/visfatin and cancer. Cancer Biol Ther 10: 119-125, 2010.

34. Li Y, Li X, Liu KR, Zhang JN, Liu Y and Zhu Y: Visfatin derived from ascites promotes ovarian cancer cell migration through Rho/ROCK signaling-mediated actin polymerization. Eur J Cancer Prev 24: 231-239, 2014.

35. Li XY, Tang SH, Zhou XC, Ye YH, Xu XQ and Li RZ: Preoperative serum visfatin levels and prognosis of breast cancer among Chinese women. Peptides 51: 86-90, 2014.

36. Nakajima TE, Yamada Y, Hamano T, Furuta K, Matsuda T, Fujita S, Kato K, Hamaguchi T and Shimada Y: Adipocytokines as new promising markers of colorectal tumors: Adiponectin for colorectal adenoma, and resistin and visfatin for colorectal cancer. Cancer Sci 101: 1286-1291, 2010.

37. Lu GW, Wang QJ, Xia MM and Qian J: Elevated plasma visfatin levels correlate with poor prognosis of gastric cancer patients. Peptides 58: 60-64, 2014

38. Sorli SC, Le Gonidec S, Knibiehler B and Audigier Y: Apelin is a potent activator of tumour neoangiogenesis. Oncogene 26 : 7692-7699, 2007.

39. Yang L, Su T, Lv D, Xie F, Liu W, Cao J, Sheikh IA, Qin X, Li L and Chen L: ERK1/2 mediates lung adenocarcinoma cell proliferation and autophagy induced by apelin-13. Acta Biochim Biophys Sin (Shanghai) 46: 100-111, 2014.

40. Heo K, Kim YH, Sung HJ, Li HY, Yoo CW, Kim JY, Park JY, Lee UL, Nam BH, Kim EO, et al: Hypoxia-induced up-regulation of apelin is associated with a poor prognosis in oral squamous cell carcinoma patients. Oral Oncol 48: 500-506, 2012.

41. Diakowska D, Markocka-Maczka K, Szelachowski P and Grabowski K: Serum levels of resistin, adiponectin, and apelin in gastroesophageal cancer patients. Disease Markers 2014: 619649, 2014.
42. Curat CA, Wegner V, Sengenès $C$, Miranville A, Tonus $C$, Busse R and Bouloumié A: Macrophages in human visceral adipose tissue: Increased accumulation in obesity and a source of resistin and visfatin. Diabetologia 49: 744-747, 2006.

43. Hivert MF, Sullivan LM, Fox CS, Nathan DM, D'Agostino RB Sr, Wilson PW and Meigs JB: Associations of adiponectin, resistin, and tumor necrosis factor-alpha with insulin resistance. J Clin Endocrinol Metab 93: 3165-3172, 2008.

44. Dalamaga M, Sotiropoulos G, Karmaniolas K, Pelekanos N, Papadavid E and Lekka A: Serum resistin: A biomarker of breast cancer in postmenopausal women? Association with clinicopathological characteristics, tumor markers, inflammatory and metabolic parameters. Clin Biochem 46: 584-590, 2013.

45. Yildiz Y, Ozaksit G, Serdar Unlu B, Ozgu E, Energin H, Kaba M and Ugur M: Serum adiponectin level and clinical, metabolic, and hormonal markers in patients with polycystic ovary syndrome. Int J Fertil Steril 7: 331-336, 2014.

46. Hebbard L and Ranscht B: Multifaceted roles of adiponectin in cancer. Best Pract Res Clin Endocrinol Metab 28: 59-69, 2014.

47. Spyridopoulos TN, Petridou ET, Skalkidou A, Dessypris N, Chrousos GP and Mantzoros CS; Obesity and Cancer Oncology Group: Low adiponectin levels are associated with renal cell carcinoma: A case-control study. Int J Cancer 120: 1573-1578, 2007.

48. Gulcelik MA, Colakoglu K, Dincer H, Dogan L, Yenidogan E and Gulcelik NE: Associations between adiponectin and two different cancers: Breast and colon. Asian Pac J Cancer Prev 13: 395-398, 2012

49. Dalamaga M, Diakopoulos KN and Mantzoros CS: The role of adiponectin in cancer: A review of current evidence. Endocr Rev 33: 547-594, 2012.

50. Izadi V, Farabad E and Azadbakht L: Serum adiponectin level and different kinds of cancer: A review of recent evidence. ISRN Oncol 2012: 982769, 2012 